\title{
Kinetics of the Steroidogenic Response to Single versus Repeated Doses of Human Chorionic Gonadotropin in Boys in Prepuberty and Early Puberty
}

\author{
LEO DUNKEL, JAAKKO PERHEENTUPA, AND DAN APTER \\ Children's Hospital [L.D., J.P.] and Department of Medical Chemistry [D.A.], University of Helsinki, \\ Helsinki, Finland
}

\begin{abstract}
There is accumulating evidence that in adult men excessive amounts of gonadotropins induce testicular desensitization to further gonadotropin stimulus. We evaluated the effects of endogenous gonadotropins and of repeated doses of exogenous human chorionic gonadotropin (hCG) on steroidogenesis by studying prepubertal and pubertal boys. The boys received either two intramuscular injections of hCG 4 days apart (protocol I) or four injections at 3- to 4-day-intervals (protocol II). In protocol I, serum testosterone, $17 \alpha$-hydroxyprogesterone, and estradiol were measured basally and for 6 days after the second injection, and in protocol II, before each injection and 4 days after the last injection. In the prepubertal-boys, serum testosterone increased from very low basal levels to 10.3 (protocol I) and $8.3 \mathrm{nmol} / \mathrm{liter}$ (protocol II). In protocol I the increase after the first injection was 64-fold and in protocol II there was an increase after each injection to a final level 144fold of the basal. No significant changes were seen in the estradiol levels. In the pubertal boys at genital stage G2, the serum testosterone levels increased after the first two injections, but at genital stage G3, the levels increased only after the first injection. Maximal testosterone increases were 27- and 8-fold, respectively. In pubertal boys estradiol levels increased progressively throughout the stimulation. The major testosterone response was seen after the first dose of hCG and repeated doses, at least in the pubertal boys, increased estradiol but not testosterone levels, thus causing an estrogen-mediated 17,20-lyase block. We therefore suggest that a single-dose hCG test deserves further evaluation for diagnostic use. (Pediatr Res 19: 1-4, 1985)
\end{abstract}

\section{Abbreviations}

APECED, aut in mune polyendocrinopathy-candidosis-ectodermal dy itr sphy

$\mathrm{E}_{2}$, estradiol

hCG, humakı chorionic gonadotropin

170HP, $17 \alpha$-hydroxyprogesterone

$\mathrm{T}$, testosterone

Chorionic gonadotropin test is a valuable clinical aid in the evaluation of Leydig cell function and, indirectly, pituitary gonadotropin secretion $(11,19)$.

Received April 24, 1984; accepted July 10, 1984.

Requests for reprints should be addressed to Dr. L. L nkel, Childre :'s Hospital, SF-00290 Helsinki 29, Finland.

This research was supported by the Sigrid Juselius F jundation and the Foundation for Pediatric Research, Finland.
Excessive amounts of gonadotropins are known to desensitize steroidogenesis in the rat and in adult men $(5,6,8,10,15,16$, 22 ). This is a complex process which includes a decrease in the activities of $17 \alpha$-hydroxylase and 17,20-lyase enzymes and an accumulation of steroid intermediates, such as progesterone and $170 \mathrm{HP}(6,8,15)$. The enzyme inhibition is thought to be mediated through the sequence of stimulation of aromatase by the gonadotropins, increased $\mathrm{E}_{2}$-production, and occupation of estrogen receptors in the Leydig cells $(4,16)$. In man, acquisition of the $E_{2}$-synthesizing capacity appears at puberty $(25,26)$, and is possibly induced by the gonadotropins.

At present little is known about the kinetics of the steroidogenic response to repeated doses of hCG in boys (9). It is of particular interest, because current protocols for diagnostic hCG stimulation test include massive and repeated doses of hCG (11, $12,19-21)$. In the present study, we investigated 1) whether repeated hCG injections might induce the $E_{2}$ response and enzyme inhibition in prepuberty and 2) how the pubertal appearance of $E_{2}$-synthesizing capacity changes the steroidogenic response to $\mathrm{hCG}$.

\section{MATERIALS AND METHODS}

Subjects. We studied 41 boys, ages 0.6 to 17.4 yr (Table 1). Thirty-two boys had heen referred to us because of suspected incomplete descent of the testis, in 17 unilateral and in 15 bilateral. In the bilateral cases all testes proved to be retractile. In the unilateral cases three testes were initially nonpalpable. All the palpable testes were of normal size (13) and consistency. Seven other boys had constitutional delay of puberty: spontaneous puberty, testes of normal size for bone-age (27), and boneage lag of at least $2 \mathrm{yr}$. They were all followed until diagnosis was clinically certain. Two boys with normal puberty had APECED (18). Twenty-five boys were prepubertal (group P1), 10 were at genital stage 2 (group P2) and six were at genital stage 3 (group P3) (24). None had received hormonal therapy. The study was approved by the Ethical Committee of the Hospital.

Protocols. We previously reported the steroidogenic response to a single dose of hCG in prepubertal and early pubertal boys (25) (Fig. 1). We now complete our study with two protocols of repeated hCG injections. In protocol I, two intramuscular injections of $5000 \mathrm{IU} / 1.7 \mathrm{~m}^{2}$ of hCG were given at $0800 \mathrm{~h} 4$ days apart. Blood was obtained immediately before both injections, and $4 \mathrm{~h}$ and $1,2,4$, and 6 days after the second injection. In protocol II, four intramuscular injections were given, on days 0 , 4,7 , and 10 . Blood was sampled immediately before each injection and 4 days after the last one.

Methods. The sera were stored at $-20^{\circ} \mathrm{C}$ until analyzed. $170 \mathrm{HP}$ and $\mathrm{T}$ were quantified by radioimmunoassay after chromatography on Lipidex-5000 (2) and $E_{2}$ after chromatography 
Table 1. Clinical findings

\begin{tabular}{|c|c|c|c|c|}
\hline Subject & Protocol & $\begin{array}{c}\text { Genital } \\
\text { stage }\end{array}$ & $\begin{array}{l}\text { Age } \\
(\mathrm{yr})\end{array}$ & Diagnosis* \\
\hline 1 & I & 1 & 0.6 & $\mathrm{~S} / \mathrm{I}$ \\
\hline 2 & I & 1 & 0.7 & $\mathrm{I} / \mathrm{S}$ \\
\hline 3 & I & 1 & 1.1 & $\mathrm{R} / \mathrm{R}$ \\
\hline 4 & I & 1 & 1.1 & $\mathrm{I} / \mathrm{S}$ \\
\hline 5 & I & 1 & 3.5 & $\mathrm{R} / \mathrm{R}$ \\
\hline 6 & I & 1 & 4.1 & $\mathrm{I} / \mathrm{S}$ \\
\hline 7 & I & 1 & 4.2 & $\mathrm{R} / \mathrm{R}$ \\
\hline 8 & I & 1 & 5.1 & $\mathrm{I} / \mathrm{S}$ \\
\hline 9 & I & 1 & 6.1 & $\mathrm{R} / \mathrm{R}$ \\
\hline 10 & I & 2 & 11.3 & $\mathrm{~S} / \mathrm{I}$ \\
\hline 11 & I & 2 & 13.7 & Delay \\
\hline 12 & II & 1 & 1.1 & $\mathrm{~S} / \mathrm{I}$ \\
\hline 13 & II & 1 & 1.1 & $-/ \mathrm{S}$ \\
\hline 14 & II & 1 & 1.2 & $\mathrm{~S} / \mathrm{I}$ \\
\hline 15 & II & 1 & 1.3 & $\mathrm{I} / \mathrm{R}$ \\
\hline 16 & II & 1 & 1.3 & S/- \\
\hline 17 & II & 1 & 2.4 & $\mathrm{R} / \mathrm{R}$ \\
\hline 18 & II & 1 & 3.5 & $R / R$ \\
\hline 19 & II & 1 & 4.6 & $\mathrm{~S} / \mathrm{I}$ \\
\hline 20 & II & 1 & 5.1 & $R / R$ \\
\hline 21 & II & 1 & 5.4 & $\mathrm{R} / \mathrm{R}$ \\
\hline 22 & II & 1 & 7.5 & $-/ \mathrm{S}$ \\
\hline 23 & II & 1 & 8.6 & $\mathrm{I} / \mathrm{S}$ \\
\hline 24 & II & 1 & 8.9 & $\mathrm{R} / \mathrm{R}$ \\
\hline 25 & II & 1 & 9.2 & $R / R$ \\
\hline 26 & II & 1 & 12.3 & $\mathrm{R} / \mathrm{R}$ \\
\hline 27 & II & 1 & 12.4 & $\mathrm{I} / \mathrm{S}$ \\
\hline 28 & II & 2 & 12.4 & $\mathrm{~S} / \mathrm{I}$ \\
\hline 29 & II & 2 & 12.4 & S/I \\
\hline 30 & II & 2 & 12.6 & APECED + \\
\hline 31 & II & 2 & 13.0 & $\mathrm{R} / \mathrm{R} \ddagger$ \\
\hline 32 & II & 2 & 14.1 & Delay \\
\hline 33 & II & 2 & 14.2 & $\mathrm{R} / \mathrm{R} \ddagger$ \\
\hline 34 & II & 2 & 14.7 & Delay \\
\hline 35 & II & 2 & 14.7 & APECED \\
\hline 36 & II & 3 & 13.9 & Delay \\
\hline 37 & II & 3 & 13.9 & Delay \\
\hline 38 & II & 3 & 14.7 & $\mathrm{R} / \mathrm{R} \ddagger$ \\
\hline 39 & II & 3 & 15.7 & Delay \\
\hline 40 & II & 3 & 16.5 & Delay \\
\hline 41 & II & 3 & 17.4 & Delay \\
\hline
\end{tabular}

* Site of the testes, left/right. S, scrotal; R, retractile; I, inguinal.

$\dagger$ Both patients had only adrenocortical insufficiency.

$¥$ Spontaneous descent of the testes occurred after the onset of puberty.

on Sephadex LH-20 (1). The same methods were used in our previous study (25).

Statistics. The data were analyzed by BMDP computer programs (7). The means were comapred by Student's $t$ test for independent and dependent samples (program 3D) and by general univariate and multivariate analysis of variance (program $4 \mathrm{~V}$ ). Because of positive skewness of the distributions, all calculations were made after logarithmic transformation.

Concentration values in $\mathrm{nmol} / \mathrm{liter}$ (pmol/liter) may be converted to $\mathrm{ng} / \mathrm{dl}(\mathrm{pg} / \mathrm{ml})$ by multiplying by $28.8(\mathrm{~T}), 33.0(170 \mathrm{HP})$, or $0.27\left(\mathrm{E}_{2}\right)$.

\section{RESULTS}

As no differences were observed in the basal or stimulated serum steroid levels between the boys with retractile testes or APECED and those with incomplete testicular descent the results were pooled for the final analysis.

Figure 1 gives the results from our previous study (solid circles)
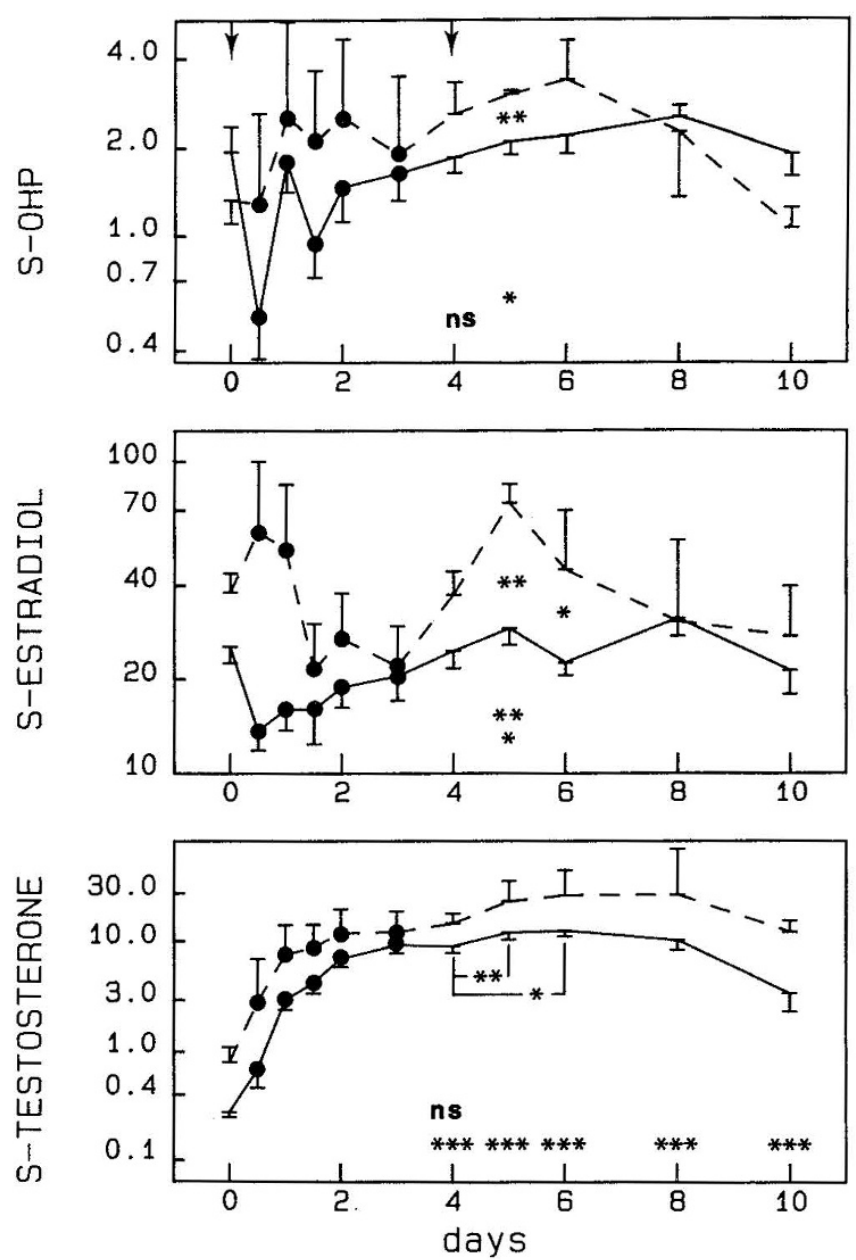

Fig. 1. Protocol I. The effect of two injections of hCG (arrows) on serum concentrations (mean $\pm \mathrm{SE}$ ) of testosterone ( $\mathrm{nmol} /$ liter), estradiol (pmol/liter) and $17 \alpha$-hydroxyprogesterone (OHP nmol/liter) in boys at genital stage $1(\mathrm{G} 1, n=9)(-)$ and $(\mathrm{G} 2, \mathrm{n}=2)(---)$. Blood samples were obtained before the injections and for 6 days after the second injection. Previous findings (Ref. 25) after an identical first dose of hCG are shown (solid circles). The asterisks between the curves indicate significant differences between the genital stages 1 and 2 , and those above the baseline significant differences from the basal level, lower row, G1; upper row, G2. Concentration values in $\mathrm{nmol} /$ liter (pmol/liter) may be converted to $\mathrm{ng} / \mathrm{dl}(\mathrm{pg} / \mathrm{ml})$ by multiplying by 28.8 (testosterone), 33.0 (OHP), or 0.27 (estradiol). ${ }^{*}, p<0.05 ;^{* *}, p<0.01{ }^{* * *}, p<0.001$.

of T, $\mathrm{E}_{2}$, and $170 \mathrm{HP}$ responses to an identical (first) dose of hCG (25). In that study, a slow (compared with adult) but very strong serum $T$ response was seen in both the prepubertal and pubertal boys. In the prepubertal boys, serum $\mathrm{E}_{2}$ and $170 \mathrm{HP}$ concentrations decreased for 6 to $12 \mathrm{~h}$ returning to basal levels within 4 days, whereas in the pubertal boys, $E_{2}$ levels were elevated for 1 day after the injection and 170HP for 4 days.

Protocol I (Fig. 1). The first injection of hCG induced a very strong serum $\mathrm{T}$ response in both groups of boys, the mean concentrations being 10.3 (prepuberty) and 16.8 (early puberty) $\mathrm{nmol} / \mathrm{liter}$. The second injection brought about a further rise to mean maxima of 14.5 and $31.5 \mathrm{nmol} / \mathrm{liter}(p<0.01$ and NS, compared with the 4 th day level), respectively, 2 to 4 days after the injection. None of the boys showed the adult-type rapid T response $4 \mathrm{~h}$ after the second injection (data not shown). In group $\mathrm{P} 1$, in contrast to the first injection, $\mathrm{E}_{2}$ levels were elevated 1 day $(p<0.05)$ after the second injection and 170HP levels, instead of decreasing as after the first injection, showed a slight, but not significant tendency to increase for 4 days. In the two early pubertal boys the second injection caused the $E_{2}$ levels to 
increase as did the first injection. 170HP levels were already elevated at the time of the second injection and remained above the prepubertal levels for 2 days thereafter.

Protocol II (Fig. 2). At all three pubertal stages studied, the main serum $\mathrm{T}$ increase was seen after the first injection, 8.6, 14.9 , and $31.4 \mathrm{nmol} / \mathrm{liter}$, or 64-, 13-, and 5-fold the basal levels in groups $P 1, P 2$, and $P 3$, respectively. In group $P 1$ the $T$ responses to the remaining injections caused a further increase in the T levels, whereas in groups P2 and P3 almost maximal levels were obtained after the second injection (Fig. 3). The maximal serum $\mathrm{T}$ concentration was attained first in group P3, next in group P2, and last in group P1. In groups P1 and P2 the maximum T levels were 17.3 and $28.8 \mathrm{nmol} /$ liter or 2.2 -fold the level reached after the first injection. In group P3 the maximum $\mathrm{T}$ level was $47.9 \mathrm{nmol} /$ liter or 1.5 -fold the level after the first injection. The difference was not significant.

In group $\mathrm{P} 1 \mathrm{E}_{2}$ levels were not affected by the two first injections but increased after the third injection $(P<0.05)$. In this group 170HP levels showed a tendency to increase, finally reaching a level significantly above the basal $(p<0.001)$. In groups P2 and P3, E 2 levels, in contrast to $T$ levels, increased after each injection. The 170HP levels increased only after the two first injections and remained elevated thereafter.
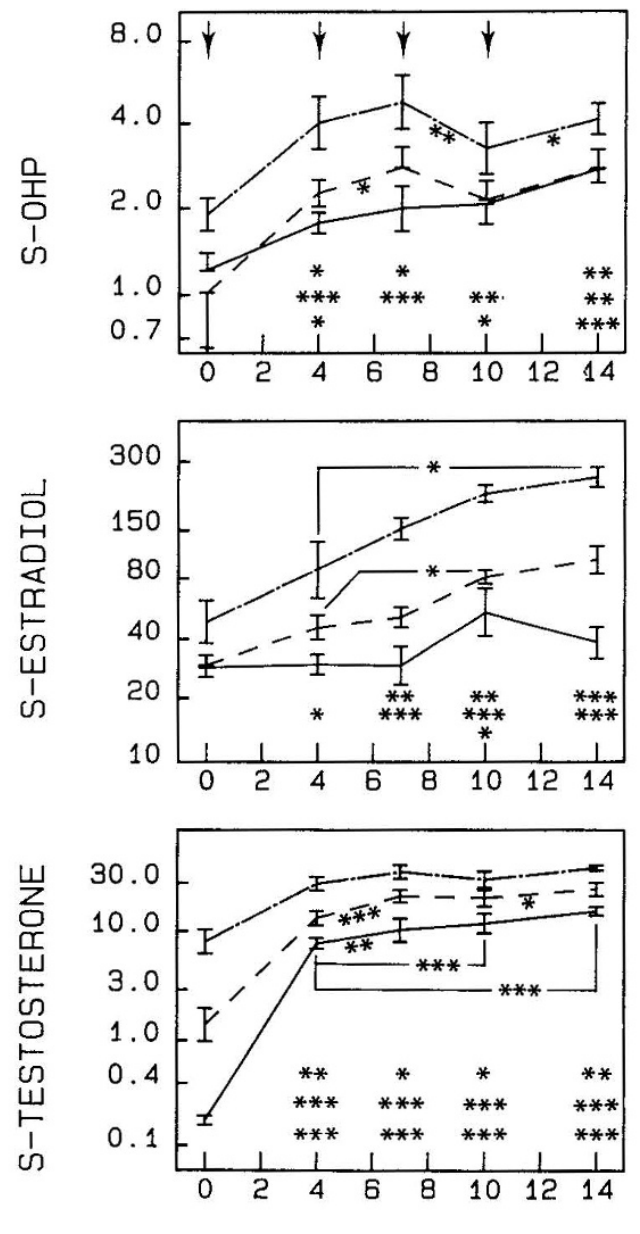

days

Fig. 2. Protocol II. The effect of four injections of hCG (arrows) given In days $0,4,7$, and 10 on serum concentrations (means $\pm \mathrm{SE}$ ) of estosterone (nmol/liter), estradiol (pmol/liter), and $17 \alpha$-hydroxyprogeserone (OHP, $\mathrm{nmol} / \mathrm{liter})$ in boys at genital stage $1(\mathrm{Gl}, n=16)(-)$, $\mathrm{G} 2, \mathrm{n}=8)(---)$, and $(\mathrm{G} 3, \mathrm{~N}=6)(-\cdot-)$. Blood was obtained before ach injection and $4 \mathrm{~d}$ after the last injection. The asterisks above the raseline indicate significant differences from the basal level, for stage $\mathrm{Gl}$ bottom row), G2, and G3 (upper row). ${ }^{*}, p<0.05 ;{ }^{* *}, p<0.01 ;{ }^{* * *} p$ $=0.001$
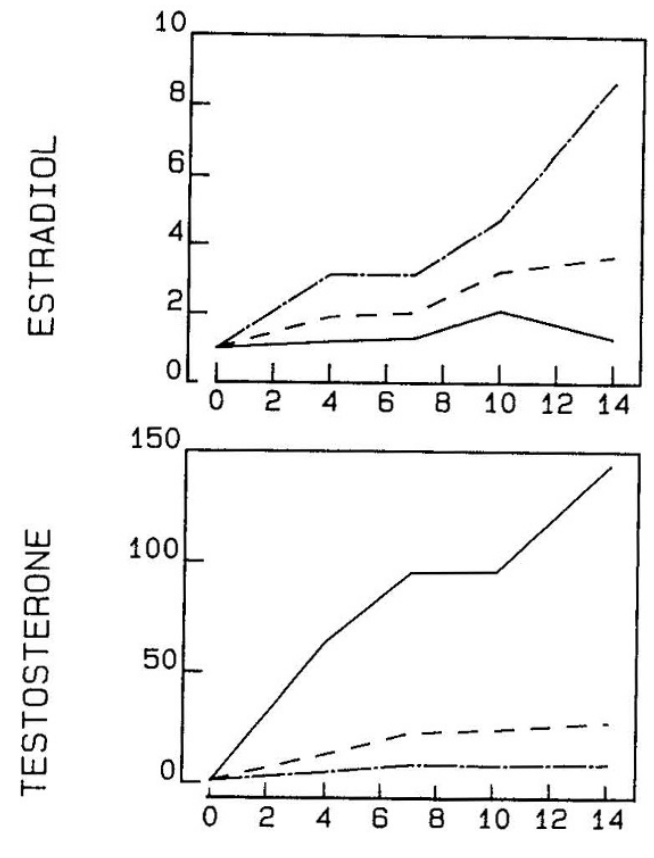

days

Fig. 3. The effect of four injections of hCG given on days $0,4,7$, and 10 on serum testosterone and estradiol levels relative to the basal level in boys for genital stage $1(\mathrm{G} 1)(-),(\mathrm{G} 2)(----)$, and $(\mathrm{G} 3)$ $(-\cdot-\cdot \cdot \cdot-)$.

\section{DISCUSSION}

For ethical reasons, we could only study boys with an evident or suspected abnormality and our groups may therefore not be completely representative of normal boys. The basal serum $T$, $170 \mathrm{HP}$, and $\mathrm{E}_{2}$ levels were not, however, different from those reported for normal boys $(3,17)$.

The present study clearly showed that in both prepuberty and early puberty the relative $T$ response was stronger to the first injection of hCG. In the steroidogenic pattern the prepubertal boys were clearly different from the pubertal boys. The relative sensitivity of the response to the first dose of hCG was significantly greater than that of the pubertal boys. Moreover, each injection of hCG clearly increased their serum T levels. As previously reported the prepubertal steroidogenic response to a single dose of hCG is fundamentally different from the adulttype of response (25). The prepubertal boys have a slow but strong $T$ response and no $E_{2}$ or $170 \mathrm{HP}$ responses. In the present study we found a small serum $E_{2}$ response 1 day after the second injection of hCG (protocol I) and a steady increase in $170 \mathrm{HP}$ during the four-injection course (protocol II). This suggests a slow induction of Leydig cell $\mathrm{E}_{2}$ synthesis with only slight consecutive inhibition of 17,20-lyase. The early pubertal boys studied with protocol I already had elevated 170HP levels after the first injection and a marked $E_{2}$ response accompanied by increasing $170 \mathrm{HP}$ levels after the second injection. This is compatible with our previous report (25) that in early puberty significant $E_{2}$ and $170 \mathrm{HP}$ responses occur after a single dose of hCG and suggests that the 17,20-lyase inhibition was thus induced by the first injection. In protocol II repeated doses of hCG were ineffective in causing a further rise in serum $\mathrm{T}$ but they did progressively increase $E_{2}$ levels, which is compatible with an estrogen-mediated augmentation of a 17,20-lyase block.

It appears that the full inhibitory effect of $E_{2}$ on $T$ synthesis only develops by puberty, and cannot be induced with prolonged $\mathrm{hCG}$ stimulation in prepuberty. Increased pubertal gonadotropin activity might have a priming effect on steroidogenesis, perhaps due to the stimulatory effect of the gonadotropins on aromatase 
activity $(15,23)$. In our study, the relative $T$ response decreased as the $E_{2}$ and $170 \mathrm{HP}$ responses increased. This may also reflect the negative testicular short-loop feed-back inhibition of $E_{2}$ on androgen production. The absolute increases in serum $T$ were smallest in prepuberty, which may reflect the small mass of potential Leydig cells (14).

Several protocols have been used for diagnostic hCG tests in boys all including repeated doses $(11,12,19-21)$. Since a single dose of hCG is sufficient to stimulate the Leydig cells in boys and, as shown in the present study, repeated injections may cause enzyme inhibition in prepuberty and definitely after the onset of puberty, we suggest that a single-dose hCG test deserves further evaluation for diagnostic use.

\section{REFERENCES}

1. Adlercreutz H, Fotsis Th, Heikkinen R 1982 Current state in the art in the analysis of estrogens. In: Görög S (ed) Advances in Steroid Analysis. Akademiai Kiado, Budapest, pp 3-33

2. Apter D, Jänne O, Vihko R 1976 Stimultaneous determination of five sex hormones in human serum by radioimmunoassay after chromatography on Lipidex-5000. Clin Chem 22:32

3. Bidlingmaier F, Versmold H, Knorr D 1974 Plasma estrogens in newborns and infants. In: Forest MG and Bertrand $J$ (eds) Sexual Endocrinology of the Perinatal Period. INSERM, Paris, pp 299-314

4. Brinkman AO, Leemborg FG, Roodnat EM, de Jong FH, van der Molen $\mathrm{HJ}$ 1980 A specific action of estradiol on enzymes involved in testicular steroidogenesis. Biol Reprod 23:801

5. Cigorrage SB, Dufau ML, Catt KJ 1978 Regulation of luteinizing hormone receptors and steroidogenesis in gonadotropin-desensitized Leydig cells. J Biol Chem 253:4297

6. Cigorrage SB, Sorell S, Bator J, Catt KJ, Dufau ML 1980 Estrogen dependence of a gonadotropin-induced steroidogenic lesion in rat testicular Leydig cells. $\mathrm{J}$ Clin Invest 65:699

7. Dixon WJ (ed) 1981 BMDP statistical software of 1981. University of California, Los Angeles

8. Dufau ML, Cigorrage S, Baukal AJ, Sorell B, Bator JM, Neubauer JF, Catt KJ 1979 Androgen biosynthesis in Leydig cells after testicular desensitization by luteinizing hormone releasing hormone and human chorionic gonadotropin. Endocrinology 105:1314

9. Forest MG, David M, Lecoq A, Jeune M 1980 Kinetics of hCG induced steroidogenic response of human testis. III. Studies in children of plasma levels of testosterone and hCG: rationale for testicular stimulation test. Pediatr Res 14:819

10. Forest MG, Lecoq A, Saez JM 1979 Kinetics of human chorionic gonadotropin induced steroidogenic response of the human testis. II. Plasma $17 \alpha$-hydroxyprogesterone, $\Delta^{4}$-androstenedione, estrone and $17 \beta$-estradiol: evidence for the action of human chorionic gonadotropin on intermediate enzymes implicated in steroid biosynthesis. J Clin Endocrinol Metab 49:284

11. Forest MG, Saez JM, Bertrand J 1973 Assessment of gonadal function in children. Paediatrician 2:102

12. Grant DB, Laurance BM, Atherden SM, Ryness J 1976 HCG stimulation tes in children with abnormal sexual development. Arch Dis Child 51:596

13. Hansen P 1952 Clinical measurements of the testis in boys and men. Acta Med Scand Suppl 142:457

14. Mancini RE, Vilar O, Lavieri JC, Andrada JA, Heinrich JJ 1963 Developmen of Leydig cells in the normal human testis, a cytological, cytochemical and quantitative study. Am J Anat 112:203

15. Martikainen H, Huhtanieni I, Vihko R 1980 Response of peripheral serum sex steroids and some of their precursors to a single injection of hCG in adult men. Clin Endocrinol 13:157

16. Nozu K, Dufau ML, Catt KJ 981 Estradiol receptor-mediated regulation of steroidogenesis in gonadotropin-desensitized Leydig cells. J Biol Chem 256:1915

17. Pakarinen A, Hammond GL, Vihko R 1979 Serum pregnenolone, progesterone, $17 \alpha$-hydroxyprogesterone, androstenedione, testosterone and $5 \alpha$-dihydrotestosterone during puberty in boys. Clin Endocrinol 11:465

18. Perheentupa J 1980 Autoimmune polyendocrinopathy-candidosis-ectoderma dystrophy (APECED). In: Eriksson AW, Forsius HR, Nevanlinna HR, Workman PL, Norio RK (eds) Population Structure in Genetic Disorders. Academic Press, London, pp 583-587

19. Perheentupa J, Dessypris A, Adlercreutz H 1972 Gonadotropin test of the functional capacity of the Leydig cells in normal and hypogonadal boys. Clin Endocrinol 1:141

20. Rivarola MA, Bergada C, Cullen M 1970 HCG stimulation test in prepubertal boys with cryptorchidism, in bilateral anorchia and in male pseudohermaphroditism. J Clin Endocrinol Metab 31:526

21. Saez JM, Bertrand J 1968 Studies on testicular function on children: Plasma concentrations of testosterone, dehydroepiandrosterone and its sulfate before and after stimulation with human chorionic gonadotropin. Steroids 12:749

22. Smals AGH, Pieters GFFM, Drayer JIM, Benraad ThJ, Kloppenborg PWC 1979 Leydig cell responsiveness to a single and repeated hCG administration. J Clin Endocrinol Metab 49:12

23. Smals AGH, Pieters GFFM, Lozekoot DC, Benraad TJ, Kloppenborg PWC 1980 Dissociated response of plasma testosterone and $17 \alpha$-hydroxyprogesterone to single or repeated human chorionic gonadotropin administration in normal men. J Clin Endocrinol Metab 50:190

24. Tanner JM 1962 Growth at Adolescence. Blackwell Scientific Publishers, London, pp 28-37

25. Tapanainen J, Martikainen H, Dunkel L, Perheentupa J, Vihko R 1983 Steroidogenic response to a single injection of $\mathrm{hCG}$ in pre- and early pubertal cryptorchid boys. Clin Endocrinol 18:355

26. Toublanc JE, Scholler R, Canlorbe P 1975 Estrogenes et testosteroné plasmatiques chez la fille normale. Applications a la pathologie. Arch Fr Pédiatr 32:941

27. Zachmann M, Prader A, Kind HP, Häfliger H, Budliger H 1974 Testicular volume during adolescence. Cross-sectional and longitudinal studies. Helv Paediatr Acta 29:61 